\title{
Peroneal muscular atrophy with pyramidal tract features (hereditary motor and sensory neuropathy type V): a clinical, neurophysiological, and pathological study of a large kindred
}

\author{
J A Frith, J G McLeod, G A Nicholson, F Yang
}

\begin{abstract}
A large family with autosomal dominant inheritance of peroneal muscular atrophy, associated with extensor plantar responses in some cases, has been studied. Onset was usually in the first two decades and spasticity was not a feature. Nerve conduction studies in 21 cases and light and electron microscope findings on six sural nerve biopsies were similar to those in hereditary motor and sensory neuropathy type II.
\end{abstract}

(F Neurol Neurosurg Psychiatry 1994;57:1343-1346)

Hereditary motor and sensory neuropathy (HMSN; peroneal muscular atrophy; Charcot-Marie-Tooth disease) is a heterogeneous group of genetically determined, slowly progressive disorders of the peripheral nerves that may be associated with extensor plantar responses in about $5 \%$ of cases. ${ }^{12}$ Dyck and Lambert ${ }^{3}$ described eight patients in two kinships who had hereditary spastic paraplegia associated with peroneal muscular atrophy and this condition was subsequently classified as HMSN Type V. ${ }^{4}$ Harding and Thomas ${ }^{2}$ in describing 25 cases from 15 families, preferred the term peroneal muscular atrophy with pyramidal features.

In the present report we describe the clinical, genetic, electrophysiological, and nerve biopsy features in a large kindred with peroneal muscular atrophy and extensor plantar responses.

\section{Methods}

PATIENTS

The family was studied in detail after the propositus was found to have the clinical features of peroneal muscular atrophy with extensor plantar responses. Nerve conduction studies were performed on affected and some unaffected members of the family and nerve biopsy was undertaken in six cases.

Neurosciences, Royal

Prince Alfred

Hospital, The

University of Sydney,

Sydney, Australia

J A Frith

J G McLeod

G A Nicholson

F Yang

Correspondence to:

Professor JG McLeod,

Department of Medicine,

University of Sydney,

NSW 2006, Australia.

Received 2 February 1994

and in revised form

9 May 1994.

Accepted 19 May 1994 and stained in $1 \%$ osmic acid for 24 hours after which single fibres were teased out. Another section of nerve was prepared for electron microscopy by fixing in 3\% glutaraldehyde in a $0.1 \%-M$ cacodylate buffer for three hours, followed by $2 \%$ osmium tetroxide for one hour. Specimens were dehydrated in graded concentrations of ethanol and embedded in epoxy resin (Spurrs). Semithin sections, $0.5-1.0 \mu \mathrm{m}$ in thickness, were stained with toluidine blue. Ultrathin sections were mounted on copper mesh grids, stained with lead citrate and uranyl acetate, and examined in a Philips 201 electron microscope.

Morphometric studies of myelinated fibres were performed on photomicrographs of toluidine-blue stained sections of two to three fascicles of each sural nerve; the numbers and diameters of the myelinated fibres were counted by a digitiser linked to a personal computer with a Sigma Scan software package programme. The numbers of unmyelinated fibres were counted and their diameters measured on electron micrographs at magnification $\times 7300$ with the same system. The numbers of denervated Schwann cell subunits and collagen pockets were also counted. ${ }^{6}$

\section{MOLECULAR GENETICS}

The CMT1A region D17S122 locus duplication was determined as previously described. ${ }^{7}$

\section{Results}

\section{CLINICAL FEATURES}

Figure 1 shows the pedigree of the family. There were 106 members, 22 of whom have had a neurological assessment performed by one of us, 21 have had electrophysiological studies performed, and six have had sural nerve biopsy. Of those examined, 15 are affected by peroneal muscular atrophy and a further 11 presumed on the basis of description by other family members to be affected giving a total of $26(25 \%)$ known affected family members ( 13 male, 13 female). Figure 1 shows that there is an autosomal dominant inheritance of the disease that affects males and females and has been expressed in five generations. Male to male transmission has occurred so that $\mathrm{X}$ linked inheritance is excluded.

The onset was usually in the first two decades with difficulty in walking. Progression was slow but in some cases (case III 16) there was moderately severe disability by the age of 30. On examination, cranial nerves were 
Figure 1 Pedigree of family

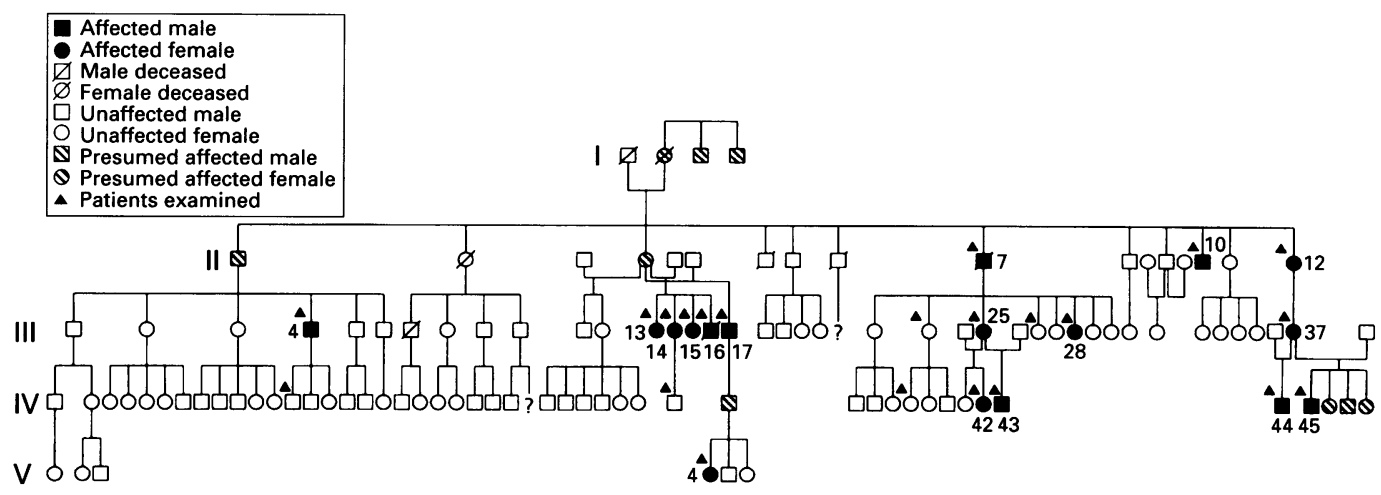

intact. Pes planus and pes cavus have been noted in different family members; there was distal wasting and weakness in upper and lower limbs, and often also proximal weakness in the lower limbs. Mild degrees of ataxia have been found in some family members. Spasticity was not found in any members of the family. Tendon reflexes were depressed or absent in the lower limbs and extensor plantar responses were present in five cases. Distal impairment of light touch and painful sensation, impaired vibration sensation at the toes, and mild impairment of position sense were commonly found.

\section{ILLUSTRATIVE CASES}

Case III 25

This woman aged 22 presented with a history of difficulty in walking since the age of 18 . Her father and cousins were similarly affected. Birth and early development were unremarkable. On examination she was below normal intelligence. She had high arched feet but no other skeletal deformity and she was ataxic on tandem gait. Cranial nerves were intact. Tone in the limbs was not increased. There was wasting of the intrinsic muscles of the hands and feet and weakness of dorsiflexion and eversion of the feet. Coordination was normal. Ankle jerks were absent and other tendon reflexes were diminished. Plantar responses were extensor. Vibration sense was absent from the toes, light touch sensation impaired to the level of the wrists and ankles, and two point discrimination increased on the feet. Position sense was intact. Peripheral nerves were not palpable. On review 14 years later she was married with three children, two of whom were affected, and there had been little change in her condition. Motor conduction velocities were mildly slowed and sensory action potentials were reduced in amplitude.

\section{Case IV 43}

A son of Case III 25 was examined. His development had been normal and there were no symptoms or abnormalities noted by the family except for flat feet. On examination, he had pes planus and thin legs with wasting of the small muscles of the hands and feet, and he could not walk on his heels. He was unsteady on tandem gait but other tests of coordination were normal. Reflexes were present but reduced. Plantar responses were extensor.
There were no sensory abnormalities detected. On review at the age of 13 there had been some progression of his distal weakness and a mild proximal weakness was also seen. There was mild slowing of motor conduction and reduced amplitude of sensory action potentials.

\section{Case III 16}

This man was seen at the age of 31 and gave a history of a difficulty in walking since the age of 17. He was moderately disabled requiring sticks and often a wheelchair. He walked unsteadily on a wide base and needed assistance to rise from a seated position. There was pes cavus. There was pronounced distal wasting in upper and lower limbs with wrist drop and foot drop. All tendon reflexes were absent. Plantar responses could not be elicited. There was mild impairment of light touch and painful sensation at the level of mid-forearm and calves. Position sense was intact, vibration sensation was absent at the toes. Motor conduction velocities were mildly slowed, and sensory action potentials were absent.

\section{Case III 37}

Clumsiness was noted in this patient about the age of 11 years and by the age of 15 she had weakness of the hands. On examination, cranial nerves were intact. There was weakness of hip flexion and dorsiflexion of the feet. There was mild incoordination of upper and lower limbs and she had a wide based ataxic gait. Tendon reflexes were absent and plantar responses were extensor. There was impairment of painful sensation on hands and feet and position sense was impaired at the toes. Motor conduction velocities were mildly slowed and sensory action potentials were reduced in amplitude.

\section{ELECTROPHYSIOLOGICAL FINDINGS}

The table summarises the results of nerve conduction studies. There was mild slowing of motor conduction velocities, although only motor conduction velocity in the median nerve and distal latency in the ulnar nerve reached statistical significance. Sensory action potentials were absent in $50 \%$ of affected family members.

HISTOPATHOLOGICAL STUDIES

Similar findings were noted in all six sural 
Nerve conduction studies in hmsn type $v$

\begin{tabular}{|c|c|c|c|c|c|c|c|c|c|c|c|c|}
\hline \multirow[b]{3}{*}{ Subjects } & \multirow[b]{3}{*}{ Age } & \multicolumn{6}{|c|}{ Motor conduction } & & \multicolumn{4}{|c|}{ Sensory conduction } \\
\hline & & \multicolumn{2}{|l|}{ Median } & \multicolumn{2}{|l|}{ Ulnar } & \multicolumn{2}{|c|}{ Common peroneal } & & \multicolumn{2}{|l|}{ Median } & \multicolumn{2}{|l|}{ Ulnar } \\
\hline & & $\begin{array}{l}\text { Latency } \\
\text { (ms) }\end{array}$ & $\begin{array}{l}\text { Velocity } \\
(\mathrm{m} / \mathrm{s})\end{array}$ & $\begin{array}{l}\text { Latency } \\
\text { (ms) }\end{array}$ & $\begin{array}{l}\text { Velocity } \\
(\mathrm{m} / \mathrm{s})\end{array}$ & $\begin{array}{l}\text { Latency } \\
\text { (ms) }\end{array}$ & $\begin{array}{l}\text { Velocity } \\
(\mathrm{m} / \mathrm{s})\end{array}$ & -. & $\begin{array}{l}\text { Latency } \\
\text { (ms) }\end{array}$ & $\begin{array}{l}\text { Amplitude } \\
(\mu V)\end{array}$ & $\begin{array}{l}\text { Latency } \\
\text { (ms) }\end{array}$ & $\begin{array}{l}\text { Amplitude } \\
(\mu V)\end{array}$ \\
\hline $\begin{array}{l}\text { HMSN V: } \\
\text { Range } \\
\text { Mean } \\
\text { SD } \\
\text { n }\end{array}$ & $\begin{array}{l}9-52 \\
28.6 \\
11.6\end{array}$ & $\begin{array}{l}2 \cdot 6-5 \cdot 0 \\
3 \cdot 7 \\
0 \cdot 7 \\
12\end{array}$ & $\begin{array}{l}42-60 \\
50 \cdot 7 \\
5 \cdot 4 \\
12\end{array}$ & $\begin{array}{l}2 \cdot 4-3 \cdot 6 \\
2 \cdot 9 \\
0 \cdot 3 \\
11\end{array}$ & $\begin{array}{c}46-60 \\
52 \cdot 7 \\
5 \cdot 4 \\
11\end{array}$ & $\begin{array}{l}3 \cdot 3-5 \cdot 8 \\
4 \cdot 9 \\
0 \cdot 8 \\
9\end{array}$ & $\begin{array}{c}39-51 \\
46 \cdot 3 \\
4 \cdot 0 \\
11\end{array}$ & & $\begin{array}{l}2 \cdot 3-3 \cdot 5 \\
2 \cdot 8 \\
0 \cdot 4 \\
7\end{array}$ & $\begin{array}{l}0-14 \\
4 \cdot 8 \\
5 \cdot 3 \\
12\end{array}$ & $\begin{array}{l}2 \cdot 0-3 \cdot 0 \\
2 \cdot 5 \\
0 \cdot 4 \\
6\end{array}$ & $\begin{array}{l}0-11 \\
2 \cdot 8 \\
3 \cdot 9 \\
12\end{array}$ \\
\hline $\begin{array}{l}\text { Controls: } \\
\text { Range } \\
\text { Mean } \\
\text { SD } \\
\text { n } \\
\text { p Value }\end{array}$ & $\begin{array}{l}18-48 \\
31 \cdot 7 \\
10 \cdot 2\end{array}$ & $\begin{array}{l}2 \cdot 5-4 \cdot 9 \\
3 \cdot 4 \\
0 \cdot 5 \\
34 \\
\text { NS }\end{array}$ & $\begin{array}{c}49-66 \\
56.9 \\
5 \cdot 0 \\
34 \\
<0.002\end{array}$ & $\begin{array}{l}2 \cdot 1-3 \cdot 7 \\
2 \cdot 6 \\
0 \cdot 4 \\
34 \\
<0.005\end{array}$ & $\begin{array}{l}47-69 \\
55 \cdot 7 \\
4 \cdot 6 \\
34 \\
\text { NS }\end{array}$ & $\begin{array}{l}3 \cdot 3-7 \cdot 7 \\
4 \cdot 6 \\
1 \cdot 0 \\
35 \\
\text { NS }\end{array}$ & $\begin{array}{l}38-56 \\
47 \cdot 3 \\
4 \cdot 9 \\
35 \\
\text { NS }\end{array}$ & & $\begin{array}{l}2 \cdot 2-3 \cdot 4 \\
2 \cdot 7 \\
0 \cdot 3 \\
15 \\
\text { NS }\end{array}$ & $\begin{array}{c}6-40 \\
22 \cdot 4 \\
8 \cdot 2 \\
15 \\
<0 \cdot 001\end{array}$ & $\begin{array}{l}2 \cdot 0-3 \cdot 1 \\
2 \cdot 4 \\
0 \cdot 3 \\
15 \\
\text { NS }\end{array}$ & $\begin{array}{c}6-36 \\
17 \cdot 1 \\
7 \cdot 2 \\
15 \\
<0 \cdot 001\end{array}$ \\
\hline
\end{tabular}
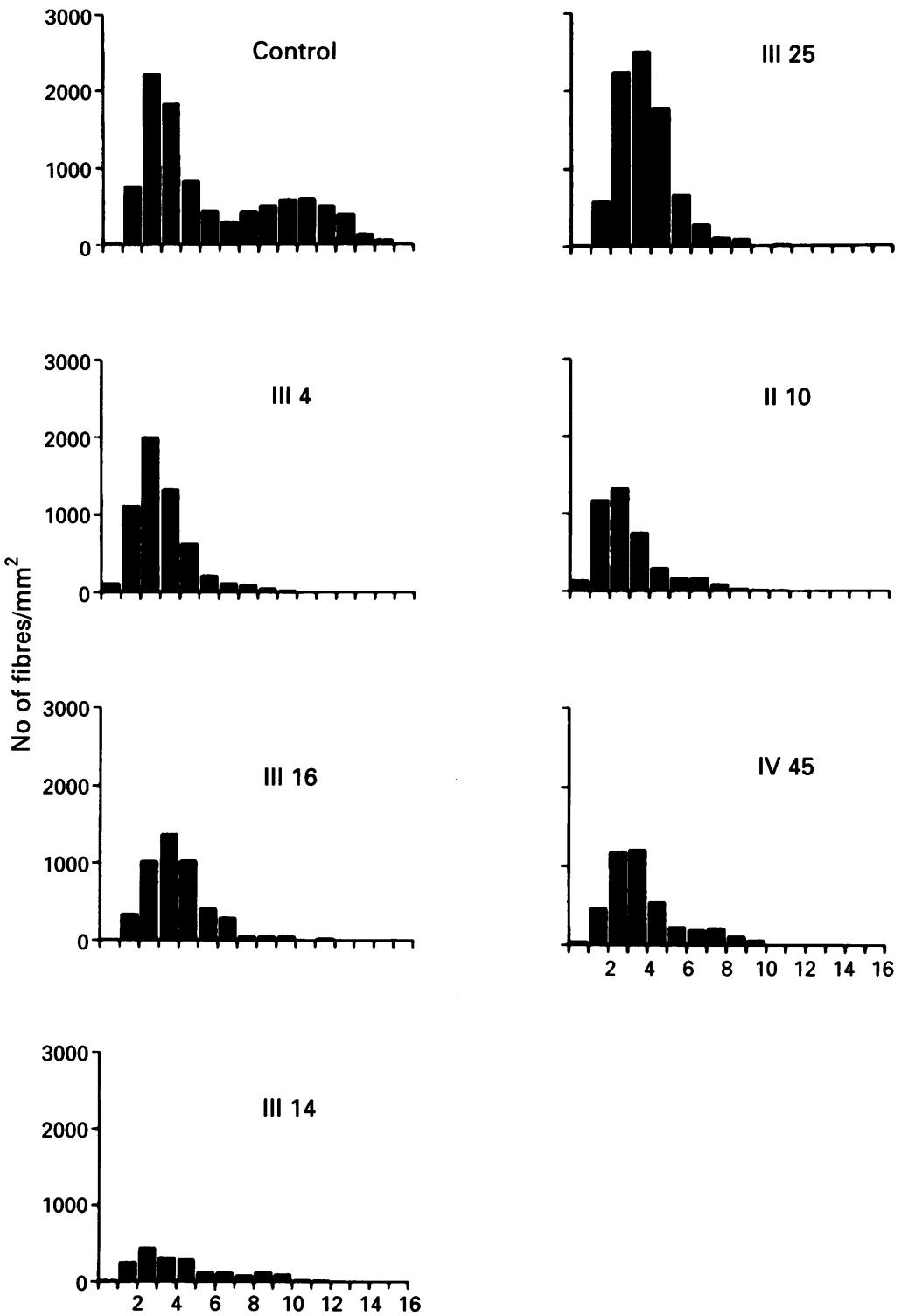

Fibre diameter $(\mu \mathrm{m})$

Figure 2 Fibre diameter distribution of myelinated fibres in the sural nerves of a control and six affected subjects. nerves (8426 (SD 2299) range 6435-12 544 fibres $\left./ \mathrm{mm}^{2}\right)$.

The density of unmyelinated fibres in the nerves of three patients ranged from $28.4 \times 10^{3}$ to $61.3 \times 10^{3}$ (mean $49.2 \times 10^{3}$ $\left(\mathrm{SD}, 18 \cdot 1 \times 10^{3}\right)$ ) fibres $/ \mathrm{mm}^{2}$. The density of unmyelinated fibres in control nerves ranged from $24.7 \times 10^{3}$ to $51.5 \times 10^{3}$ (mean, $38.0 \times 10^{3}\left(\mathrm{SD} 9.5 \times 10^{3}\right)$ ) fibres $/ \mathrm{mm}^{2}{ }^{6}$ The difference is not significant $(p>0.05)$. The fibre diameter distribution was similar in the two groups (fig 3).

The density of denervated Schwann cell subunits in nerves of three patients ranged from 3.1 to 7.9 (mean 4.9 (SD 2.5)) $\times 10^{3}$ subunits $/ \mathrm{mm}^{2}$. The density in control nerves ranged from 1.8 to 5.5 (mean 4.3 (SD $1.5)) \times 10^{3}$ subunits $/ \mathrm{mm}^{2}{ }^{6}$ The difference is not significant $(p>0.05)$. The density of collagen pockets in the nerves of three patients ranged from 5.3 to 14.5 (mean, $9.01(\mathrm{SD}, 4 \cdot 8)) \times 10^{3} / \mathrm{mm}^{2}$. The range in control nerves was 3.5 to 9.1 (mean 5.7 (SD $2 \cdot 2)) \times 10^{3} / \mathrm{mm}^{2} .{ }^{6}$ The difference is not significant $(\mathrm{p}>0.05)$.

DNA STUDIES

Blood was examined from four members of the family. Two cases were uninformative, and the other two showed no duplication at the D17S122 locus.

\section{Discussion}

Harding and Thomas ${ }^{2}$ accepted a diagnosis of peroneal muscular atrophy with pyramidal tract features if at least two affected members of the family had extensor plantar responses. This family, with peroneal muscular atrophy, satisfies their criterion, as five members have unequivocal extensor plantar responses. The onset in most cases was in the first two decades, a finding similar to that reported in other families ${ }^{23}$ although in some of our cases and those in other reports, the first symptoms were experienced later in life. ${ }^{8}$

The clinical expression of pyramidal tract involvement varies in different pedigrees. In our family, tendon reflexes were not increased and there was no spasticity, but plantar responses were extensor. In the cases described by Harding and Thomas ${ }^{2}$ and Schnider and colleagues ${ }^{8}$ tendon reflexes were 

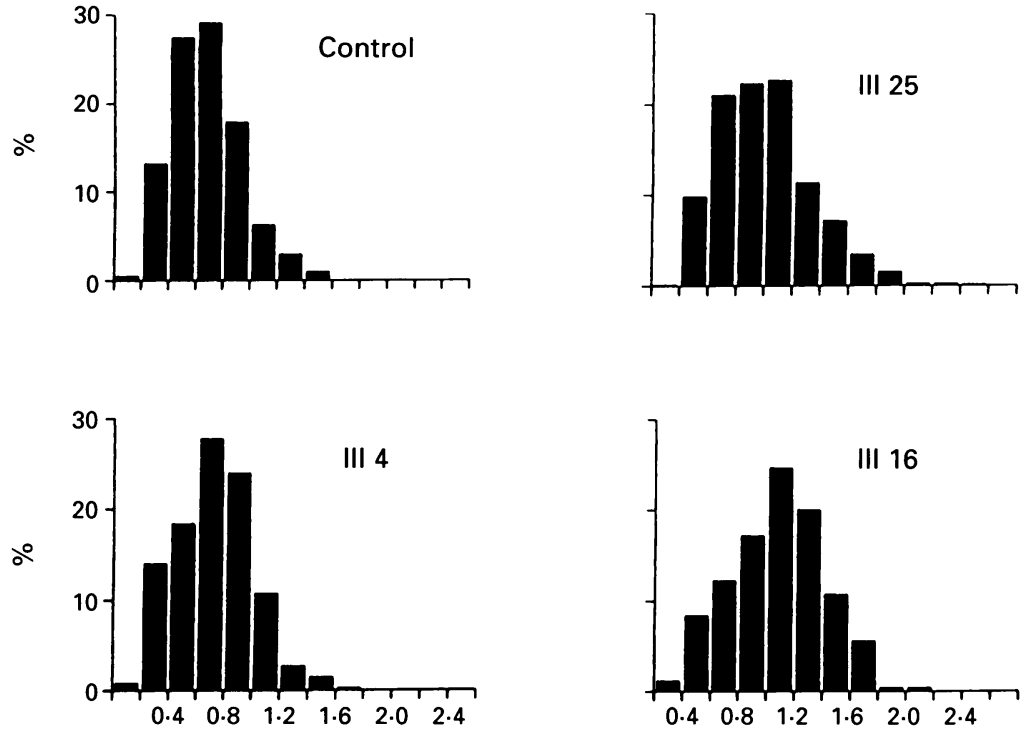

Fibre diameter $(\mu \mathrm{m})$

Figure 3 Distribution of diameters of unmyelinated fibres in the sural nerves of a control and three affected subjects. colleagues $^{9}$ found pronounced slowing of conduction consistent with HMSN I in four cases.

There have been no necropsy studies of HMSN V but there is clinical evidence consistent with degeneration of the corticospinal tracts. This conclusion is supported by studies with magnetic transcortical motor stimulation that have shown prolongation of conduction times in affected subjects but not in patients with pure HMSN I and II. ${ }^{89}$

In this large family with HMSN $\mathrm{V}$ there seems to be an autosomal dominant mode of inheritance. Electrophysiological studies were not performed on all members of the family, many of whom were unavailable, and some affected members may have been overlooked because of the mildness of their symptoms. Not all members of the family had extensor plantar responses, probably because of variable expression of the gene or because of muscle wasting involving the extensor hallucis longus muscle. The clinical, electrophysiologi$\mathrm{cal}$, and pathological features in this family are those of HMSN II associated with pyramidal tract involvement. Studies on DNA showed no duplication of the D17S122 locus, excluding the diagnosis of the common form of HMSN IA, a finding that was expected as there was no electrophysiological or pathological evidence of demyelination. Linkage elsewhere to chromosome 17 is not excluded as insufficient DNA samples were available for linkage studies. absent or normal and in no cases were they increased. By contrast, spasticity and hyper-reflexia were notable features in the cases reported by Dyck. ${ }^{4}$ Some earlier workers reported spastic paraplegia associated with amyotrophy ${ }^{10-12}$ but electrophysiological studies were not performed in these families and the muscle wasting may not necessarily have been caused by peripheral neuropathy. It is possible that there are at least two distinct genetic types of HMSN V, one with spasticity and minor amyotrophy, and the other without spasticity and more pronounced muscle wasting.

The peripheral nerve conduction studies in our family showed normal or only mildly slowed motor conduction with reduced amplitudes of sensory action potentials, findings that are consistent with HMSN II. ${ }^{1313}$ The pathological findings in the sural nerve biopsies of reduction of myelinated fibres of all diameters and absence of significant demyelination on teased fibre studies were identical to those in HMSN II. ${ }^{4}$ Also, we found no onion bulb formations on electron microscopy, and normal densities and fibre diameter distributions of unmyelinated fibres. Morphometric studies of collagen pockets and empty Schwann cell subunits did not indicate loss of unmyelinated fibres. There have been few previously reported studies of sural nerve pathology in HMSN V and these have also shown similar features to those of HMSN II. ${ }^{414}$ Although all the cases so far studied have pathological features of a neuronal type of atrophy and most of these have electrophysiological features compatible with this pathology, it should be noted that Claus and

1 Harding AE, Thomas PK. The clinical features of hereditary motor and sensory neuropathy types I \& II Brain 1980;103:259-80.

2 Harding AE, Thomas PK. Peroneal muscular atrophy with pyramidal features. $f$ Neurol Neurosurg Psychiatry 1984;47:168-72.

3 Dyck PJ, Lambert EH. Lower motor and primary sensory neurone diseases with peroneal muscular atrophy. II Neurologic, genetic and electrophysiologic findings in various neuronal degenerations. Arch Neurol 1968;18: 619-25.

4 Dyck PJ. Inherited neuronal degeneration and atrophy affecting peripheral motor, sensory and autonomic neurons. In: Dyck PJ, Thomas PK, Lambert EH, eds. Peripheral neuropathy. Philadelphia: WB Saunders, 1975 825-67.

5 Yiannikas C, McLeod JG, Walsh JC. Peripheral neuropathy associated with polycythemia vera. Neurology 1983;33: 139-43.

6 Low PA, McLeod JG, Prineas JW. Hypertrophic CharcotMarie-Tooth disease. Light and electron microscope studies of the sural nerve. $\mathcal{F}$ Neurol Sci 1978;35:93-115.

7 Nicholson GA, Kennerson ML, Keats B, Mesterovic N, Churcher W, Barker D, Ross DA. The Charcot-MarieTooth neuropathy type 1A mutation: apparent Tooth neuropathy type $\mathrm{A}$ mutation: apparen Med Genet 1992;44:455-60.

8 Schnider A, Hess CW, Koppi S. Central motor conduction in a family with hereditary motor and sensory neuropathy with pyramidal signs (HMSN V) $\mathcal{f}$ Neuro Neurosurg Psychiatry 1991;54:511-5

9 Claus D, Waddy HM, Harding AE, Murray NMF, Thomas PK. Hereditary motor and sensory neuropathies and hereditary spastic paraplegia; a magnetic stimulation study. Ann Neurol 1990;28:43-9.

10 Garland HG, Astley CE. Hereditary spastic paraplegia with amyotrophy and pes cavus. I Neurol Neurosurg Psychiatry 1950;13:130-3.

11 Dick AP, Stevenson CJ. Hereditary spastic paraplegia. Report of a family with associated pyramidal signs. Lancet 1953;i:921-3.

12 Silver JR. Familial spastic paraplegia with amyotrophy of the hands. I Neurol Neurosurg Psychiatry 1966;29: 135-44.

13 Thomas PK, Calne DB. Motor conduction velocity in peroneal muscular atrophy: evidence for genetic heterogeneity. F Neurol Neurosurg Psychiatry 1974;37:68-75.

14 Behse F, Buchthal F. Peroneal muscular atrophy (PMA) and related disorders. II Histological findings in sural nerves. Brain 1977;100:67-85. 